\title{
Attitudes Toward Abortion Among Religious Traditions in the United States: Change or Continuity?
}

John P. Hoffmann

Brigham Young University - Provo, john_hoffmann@byu.edu

Sherrie Mills Johnson

Brigham Young University - Provo

Follow this and additional works at: https://scholarsarchive.byu.edu/facpub

Part of the Family, Life Course, and Society Commons, Medicine and Health Commons, and the Sociology of Religion Commons

\section{Original Publication Citation}

Hoffmann, John P., and Sherrie Mills Johnson. 2005. "Attitudes toward Abortion among Religious Traditions in the United States: Change or Continuity?" Sociology of Religion 66(2):161-182.

\section{BYU ScholarsArchive Citation}

Hoffmann, John P. and Johnson, Sherrie Mills, "Attitudes Toward Abortion Among Religious Traditions in the United States: Change or Continuity?" (2005). Faculty Publications. 3919.

https://scholarsarchive.byu.edu/facpub/3919

This Peer-Reviewed Article is brought to you for free and open access by BYU ScholarsArchive. It has been accepted for inclusion in Faculty Publications by an authorized administrator of BYU ScholarsArchive. For more information, please contact ellen_amatangelo@byu.edu. 


\title{
Attitudes Toward Abortion Among Religious Traditions in the United States: Change or Continuity?
}

\author{
John P. Hoffmann* \\ Brigham Young University
}

and

Sherrie Mills Johnson

Brigham Young Uniwersity

Abortion continues to be a highly contentious issue in the United States, with few signs of abatement. The goal of this paper is to specify how variable positions about abortion across religious traditions have led to differential shifts in attitudes among their members. Based on culturally relevant events, position papers, and other religious media, the guiding hypotheses propose that Evangelicals have become increasingly opposed to abortion for elective reasons; yet changes in attitudes regarding abortion for traumatic reasons are due primarily to cohort shifts. Data from the cumulative General Social Surveys (1972-2002) are used to test the hypotheses. The first hypothesis is supported: Opposition to elective abortions among Evangelicals has increased relative to other religious traditions. However, contrary to the second hypothesis, they have also become more opposed to abortion for traumatic reasons. This increasing opposition is most prominent among Evangelicals born in the last 40 years or so. Implications for understanding Evangelical distinctiveness and the cultural context of abortion attitudes are discussed.

Abortion continues to be a highly contentious issue in the United States, with few signs of abatement. Historical evidence mapping the past 30-40 years indicates that there has been variable interest in the abortion debate among

*Direct correspondence to: John P. Hoffmann, Department of Sociology, Brigham Young University, Provo, UT 84602; email: John_Hoffmann@byu.edu. Earlier versions of this paper were presented at the annual meeting of the Association for the Sociology of Religion, Chicago, IL, August 2002; and at the Population Research Center, University of TexasAustin, January 2003. We thank the following people for valuable comments and insights about earlier drafts of this paper: Mikaela Dufur, John Evans, Cardell Jacobson, John Bartkowski, Mark Regnenus, Chris Ellison, and Christine Horne. 
assorted groups, with several placing it at the forefront of their agendas. Isolating the key sub-issues in the abortion controversy is difficult, however, because it is a legal, political, and social issue that transcends many fundamental dimensions, including moral, familial, human rights, and the variety of worldviews that exist in contemporary society. In brief, the struggle over abortion is a cultural issue par excellence. Not only is it highly symbolic, but, as a cultural marker, it also cuts to the core of people's attitudes toward life, moral behavior, and the fettering of freedom (Hunter 1994; Dillon 1995, 1996; Rudy 1996; Russo and Denious 1998).

Religious traditions have clearly played an important role in the abortion debate. Several have served as centers of moral outrage over the prevalence of abortions in the U.S. (e.g., Falwell 1986; Schlossberg and Achtemeier 1995); yet, certain groups have also raised strong arguments in favor of a pro-choice position. ${ }^{1}$ Abortion is the pivotal issue that brought Protestant Fundamentalists into the political fray at the national level. It also motivated the founding of the Moral Majority in the 1970s (Falwell 1986). Debates about abortion have served to polarize the Catholic community. Although the official policy of the Catholic Church involves an extreme pro-life position (Jung and Shannon 1988), there is considerable within-group diversity that has increased over the last 30 years (Hoffmann and Miller 1998; Evans 2002). There is also evidence that the abortion issue has led to a reconfiguration of political affiliation among several groups, with those advocating a pro-life position becoming increasingly allied with the Republican Party (Wilcox 1995). Nevertheless, a considerable number of religious organizations have shied away from the debate, arguing that although the moral concerns are formidable it is up to each person's conscience to decide the proper course of action regarding abortion (e.g., Heim 1988; Presbyterian Church-USA 1992).

The goal of this paper is to specify how the variable positions about abortion across religious traditions have led to differential shifts in attitudes among their members. Although there has been considerable attention paid to this issue, we contend that some important nuances have not been addressed. In particular, abortion attitudes over the last $30-35$ years have become more sensitive to the types of abortion that are considered (Luker 1984; Petersen 2001). This is affected by the rhetoric used to address the abortion issue by religious groups. The most vociferous attention has focused on elective abortion because it involves what many consider as a culpable act on the part of the pregnant woman (Christianity Today 1984; Dunnett 1990; Christian Century 1991; Woodrum and Davison 1992). Thus, we submit that most of the shifts in attitudes about abortion-including an increasing gap of support or opposition by different reli-

${ }^{1}$ We use the terms "pro-choice" and "pro-life" in this paper not in an evaluative sense, but rather as convenient and well-known terms that identify general attitudes toward abortion. 
gious traditions-have concerned elective rather than traumatic abortion. ${ }^{2}$ Before approaching this issue empirically, the following sections discuss the variable attention paid by religious traditions to the abortion issue and how this may have affected shifts in attitudes.

\section{ABORTION AND RELIGIOUS TRADITIONS}

Given the cultural complexities of the abortion issue, it is not surprising that Catholics are not the only group to find themselves in an internal struggle over abortion policy. Other groups that have often been perceived as maintaining a strong pro-life position, such as Southern Baptists and the Church of the Brethren, have also experienced conflicts about abortion. Ammerman (1990), for example, links increasing turmoil in the Southern Baptist Convention during the 1980 s to its perceived shift toward a more absolute pro-life position.

Although the diversity of abortion attitudes within religious traditions is an important topic (Hoffmann and Miller 1998; Smith 2000; Evans 2002), especially when one considers the presumed culture wars that may be taking place in the U.S. (cf. Hunter 1994; Nolan 1996; McConkey 2001; Mouw and Sobel 2001), intergroup positions and whether they have moved during recent periods of variable interest in abortion remains a significant issue. Numerous studies have found supporting and contrary evidence regarding whether attitudes about abortion have shifted (e.g., Harris and Mills 1985; Dillon 1996; Hoffmann and Miller 1997). Studies indicate that Evangelicals and members of other conservative religious traditions remain highly opposed to most types of abortion, although several groups appear to have become slightly more permissive about abortion.

It is our contention, however, that most of the empirical research has missed some essential characteristics of these proposed shifts. In particular, if abortion is fundamentally a cultural issue, then we should search conceptually for how it is defined and perceived by society and by constituent groups. The abortion issue has several more layers than might be assumed by those who use labels such as pro-choice or pro-life (Hunter 1994; Rudy 1996). Although many observers assert implicitly that people's thoughts about abortion are monolithic, they obviously are not. Moreover, a monolithic view masks important issues of cultural change that affect whether and in what manner positions shift over time. The next section explores the texture of abortion attitudes in detail to demonstrate that, as a cultural issue, there is actually more than one layer that should be investigated if we are to identify and understand shifting attitudes among religious traditions over time.

${ }^{2}$ Various studies have discussed the distinctions between elective and traumatic abortions in detail (see, e.g., Harris and Mills 1985; Jelen 1988; Cook, Jelen, and Wilcox 1992; Petersen 2001). 


\section{THE CULTURAL CONTEXT OF ABORTION ATTITUDES AMONG RELIGIOUS TRADITIONS}

A fundamental question is whether the ebbs and flows of interest about abortion have affected changes in attitudes among members of religious traditions. There is some literature that suggests that abortion attitudes have shifted toward a slightly more permissive viewpoint over the past 30 years (Hoffmann and Miller 1997). However, younger age cohorts have become slightly less permissive (Sullins 1999). The modest nature of these shifts cannot be ignored, however. Cultural shifts are slow and fundamental worldviews that involve a right-to-life for fetuses or a right to personal freedom for women have maintained their hold on many people. Certain religious groups, especially those that are strict or sectarian, have a clear vision about when life begins and, accordingly, their members continue to oppose abortion in most forms. This moral position has led to relatively consistent anti-abortion attitudes that persisted during the latter part of the 20 th century. Although other groups that do not make absolute claims about when life begins or when protection of the fetus overcomes the mother's interests may have seen some movement in attitudes over time, it has not been impressive. Religious traditions that are labeled mainline, liberal, or moderate have maintained an ambivalent stance about abortion.

A review of the positions of various groups demonstrates the dubiousness of such a sweeping argument. It is clear that most groups have changed their position to some degree about abortion. Some groups, such as the Southern Baptist Convention, adopted more extreme pro-life language about abortion during the 1980s (Ammerman 1990). Others, such as the American Baptist Church, the Reformed Church of America, and the Evangelical Lutheran Church, also moved away from a pro-choice position about abortion, especially during the 1980s (Christianity Today 1984; Heim 1988). Advocacy groups founded in the late 1970s and early 1980s by members of conservative religious organizations, such as Focus on the Family and Concerned Women for America, made opposition to abortion one of their founding principles. On the other hand, the Presbyterian Church-USA, the Episcopal Church USA, and several other religious organizations issued policy statements in the 1980s and early 1990s that argued against legal sanctions for most abortion services. Although this did not necessarily herald shifts in official church positions, there was a clear message that abortion is a personal decision that should be unaffected by official government policy (Frame 1989; Presbyterian Church-USA 1992). Moreover, during the mid-1970s the National Council of Churches (NCC) recommended shifting toward a more permissive view of abortion. Its proposed policy statement-which was met with some opposition from the Episcopal and the Greek Orthodox churches - stated that a woman's wishes should be paramount in decisions about abortion (Kucharsky 1973).

A careful reading of these policy statements and other internal documents, however, reveals an important component that should not be ignored. That is, 
except for a couple of religious organizations, almost all groups distinguish the type of abortion that is morally acceptable or impermissible. Moreover, groups' reactions to policy shifts about abortion clearly have been sensitive to the circumstances motivating a hypothetical woman's abortion decision. Roe v. Wade set a legal precedent that relied on the timing of the abortion by establishing trimesters during which the strength of government interest engages at increasing levels. Yet public opinion and internal documents of religious and other groups indicate plainly that the decisive element that drives attitudes and policy preferences about this issue is whether abortion is for elective reasons or for traumatic reasons. For example, empirical studies of abortion attitudes suggest that many of those in the pro-choice camp resist government intervention regarding abortion but are morally opposed to it as a method of birth control (Scott 1989; Woodrum and Davison 1992). Furthermore, several studies have discriminated empirically between attitudes toward elective and traumatic abortion, and have shown that these sets of attitudes have different correlates (e.g., Cook, Jelen, and Wilcox 1992; Jelen and Wilcox 1997). ${ }^{3}$ A key distinguishing feature involves the presumed blameworthiness or responsibility for the pregnancy. Elective reasons for abortion such as when a woman doesn't want any more children are presumed as, at least, the partial responsibility of the woman and therefore garner less moral sympathy from observers. On the other hand, when the reasons involve traumatic circumstances such as rape, incest, severe fetal deformity, or risks to the mother's life, the decision of whether or not to abort shifts, in a moral sense, to the woman's personal sphere (Zucker 1999).

At the cultural level, these distinctions affect the way that abortion is perceived symbolically and how it is discussed by different groups. Although there are differing worldviews about the ultimate importance of the fetus, most religious groups go to great lengths to distinguish elective and traumatic abortions both morally and politically. For example, Evangelical, Fundamentalist, and Catholic literature (at least the official literature of the Roman Catholic Church) dismiss quite readily arguments about elective abortion. This literature consistently points out that abortion for elective reasons-or what is often termed abortion as birth control-is by far the most common type. And, according to this literature, it is clearly an indicator of the moral decline of society (Powell 1981;

${ }^{3}$ An inconsistency in the social scientific literature is whether one, two, or more latent constructs underlie abortion attitudes in the U.S. Studies using Mokken analysis indicate that a single dimension summarizes attitudes toward abortion (e.g., Gillespie, Ten Vergert, and Kingma 1987, 1988). Studies using latent class analysis or factor analysis show that two dimensions underlie attitudes toward abortion (e.g., Petersen 2001). Others argue that there are several dimensions that underlie the abortion issue (Hunter 1994). We see most of these attempts at conceptualizing abortion attitudes as the statistical tail wagging the conceptual dog. Statistical approaches to measurement issues are often not grounded well in a solid conceptualization of the issues (Sørenson 1998). There is clearly a cognitive and cultural distinction, at the very least, between attitudes about abortion for elective or for traumatic reasons (see, e.g., Luker 1984; Rudy 1996). 
Falwell 1986; Dobson 1988; Jung and Shannon 1988; Lewis 1997). However, the more conservative groups also discuss the difficulties inherent in decisions about traumatic abortion. Some groups argue that abortion for these reasons is so rare that designing policy for them should be given minimal attention. Groups such as the Seventh-day Adventists (1992) and the Assemblies of God (1985), on the other hand, have issued position papers that discuss when abortion may be permissible, such as when the pregnancy threatens the life of the mother or when the pregnancy occurs as the result of a rape or incest. Others have tepidly argued against abortion for traumatic reasons, yet place a large bulk of their attention on elective abortions (Jung and Shannon 1988; Lewis 1997).

Religious traditions that are considered more moderate in their approach to social and political issues also distinguish between abortion for elective and traumatic reasons. The Presbyterian Church-USA, the United Methodist Church, and the American Baptist Church, for instance, issued policy statements in the 1980s and 1990s denouncing abortion for elective reasons, yet they either did not propose government prohibition or they opposed criminal penalties for those who performed or sought abortions (Heim 1988; Frame 1989; Presbyterian Church-USA 1992). All of these groups, as well as several others, also maintain that abortion for traumatic reasons involves a decision best left to the woman and her medical advisers (e.g., Presbyterian Church-USA 1992; United Methodist Church 2000). Since most attitudinal items that ask about abortion specify its legal availability, it is likely that members of more conservative and more moderate denominations differ in their attitudes toward elective or traumatic abortions. However, an important question that remains is whether attitudes have shifted differentially over time and across groups as the broader cultural; social, and political landscape has changed in the U.S. over the past 30 years or so.

\section{CULTURAL CHANGE AND ABORTION ATTITUDES AMONG RELIGIOUS TRADITIONS}

Culture moves, albeit slowly. Indicators of cultural change are numerous, but typically are identified as general concepts that spread to specific political and social spheres of influence (Rochon 1998). These concepts may be reinforced or undermined by specific decisions or movements among elite institutions. Moreover, "critical communities," which include religious organizations, affect cultural change by shifting the symbols and dialogue about specific issues (Rochon 1998). Clearly this has occurred in the abortion debate, especially in its early stages, as the symbolic underpinnings of abortion were redirected in the late 1960s and early 1970s from protection of an unborn "life" to women's rights to control their bodies and their lives (Luker 1984). Attention to the unborn "life" was not abandoned, however; many critical communities continued to use the symbol of fetus-as-a-life in dramatic fashion. The use of different symbols that dictate the texture of the debate has continued for the past 30 years. 
Nevertheless, the success of advocacy groups at differentially emphasizing these symbols and worldviews has shifted over time. O'Connor (1996) has partitioned the period from the early 1970 s to the early 1990 s and discussed the relative success of pro-choice and pro-life groups. She claims that before the mid1970s the pro-choice forces had the upper hand, especially when Roe v. Wade circumscribed state interest in prohibiting legal abortions. From the mid-1970s to the late 1980s pro-life advocates organized and were successful at shifting the debate toward the "moral injustices" wrought by the widespread availability and use of abortion. They found political and moral support in the Reagan administration's anti-abortion stance. The founding of anti-abortion organizations such as Concerned Women for America heralded a high point for the pro-life community. The late 1980s and early 1990s saw the pendulum swing back to the prochoice position as groups such as the Moral Majority disbanded and as the Bush administration paid more attention to foreign affairs than to these moral issues.

The 1990s was a period of uncertainty about abortion, but the balance probably tipped in favor of the pro-choice camp. The Webster (1989) and Casey (1992) Supreme Court decisions provided limitations to a broad pro-choice position, but they did not go far enough to satisfy most of those in the pro-life camp. For example, neither case addressed directly the issue of elective abortions, even though, as shown above, this issue has garnered the greatest displeasure from conservative religious traditions. The cases also left only a small window through which more extreme anti-abortion measures might fit. The Clinton administration was perceived as far too pro-choice for most conservative religious groups, with many feeling betrayed by a President who claimed to be a Southern Baptist, but was seen as supporting far-reaching abortion rights (Yancey 1994).

But pro-choice advocates could not claim victory either; the Supreme Court-and most state legislatures - was unwilling to expand abortion rights and, although Clinton was ostensibly pro-choice, he passed few measures to broaden access to abortion. The defeat of the Freedom of Choice Act in 1993, even though it initially had Clinton's support, was a devastating blow for abortion rights advocates. Hence, we suspect that, if there has been a divergence of attitudes among conservative religious traditions and other religious adherents in the U.S., it emerged primarily in the late 1980s and 1990s. This was a period of conservative retrenchment about certain moral issues such as abortion (cf. Smith 2000), during which an ideological consistency about abortion took hold among conservative groups that led to increasing opposition to legal abortion (Huckfeldt and Sprague 2000). It is likely that earlier periods were marked by a status quo or a conservative/moderate/liberal "stand-off" in terms of attitudes toward abortion. Moreover, the last 15 years or so have also seen Evangelicals taking their religion "public," by engaging in a greater role in addressing presumed social and political injustices (Regnerus and Smith 1998). Abortion is a leading "injustice" that is addressed by numerous Evangelical groups. Strong opposition allows the Evangelical community to demonstrate its distinctiveness from the rest of a society seen as experiencing moral decline. 
An important qualification to this general hypothesis is that it pertains to attitudes toward elective abortions only. As discussed above, most religious traditions go to some measure to ensure that their rhetoric and policy preferences distinguish abortion for elective and traumatic reasons. Few religious organizations completely prohibit abortion; hence there is likely more ideological inconsistency within groups when considering abortion for traumatic reasons (cf. Huckfeldt and Sprague 2000). Moreover, since much of the debate about abortion among religious groups tacitly concerns elective abortions (Jelen 1988), it is unlikely that divergence of views has occurred for abortion for traumatic reasons. Rather, inasmuch as most religious groups-even many that are orthodox or conservative-accept moral arguments that allow abortion for traumatic reasons, we suspect that any change in the relative position of groups is modest. Most of the change in attitudes toward abortion for traumatic reasons is probably due to cohort shifts, with more recent birth cohorts more supportive of abortion for these reasons (cf. Cook, Jelen, and Wilcox 1993). This is because more recent cohorts have become accustomed to a worldview that supports the rights of women to control their bodies, especially when they are not responsible for pregnancies or when their health is in danger (Rochon 1998; Zucker 1999).

In sum, primarily for cultural reasons, we differentiate between attitudes toward abortion for elective and traumatic reasons and propose the following hypotheses. First, we expect that attitudes toward legal abortion for elective reasons have diverged across Evangelical groups and more moderate religious groups, with the former increasing in their opposition relative to the generally more permissive stand among other groups. This divergence became most prominent in the late 1980s and 1990s for the reasons outlined above. Second, we propose that while Evangelical groups are more opposed to abortion for traumatic reasons than other groups, their relative positions have not changed. The primary divergence has occurred across birth cohorts as younger cohorts have become more likely than older cohorts to support legal abortions for traumatic reasons.

\section{DATA AND METHODS}

In order to test these hypotheses, we use data from the 1972-2002 General Social Surveys (GSS), repeated cross-sectional surveys that have been conducted at annual or two-year intervals for a substantial period. The GSS collects data on numerous variables including demographics, religious affiliation and behavior, and attitudes toward a number of social issues. It has been used in numerous studies to investigate abortion attitudes in the U.S. (e.g., Jelen 1988; Sullins 1999; Petersen 2001; Evans 2002). The sample sizes vary across the years, although most years have approximately 1,500 respondents who represent the noninstitutionalized population of the United States ages 18 and older. Our goal is to determine changes over time in attitudes toward elective and traumatic abortion; hence we use the cumulative file that spans the time period of interest. 
Since we are interested primarily in those respondents who are active members of their faiths, we restrict the analysis to those who report attending religious services at least one time per month (e.g., Evans 2002). A reasonable assumption is that those who attend religious services are more sensitive to the messages provided by their group; hence, changes in attitudes towatd abortion that are susceptive to the messages delivered by religious organizations will be affected primarily among those who are actively involved in the organization. Limiting the sample to those who attend religious services, combined with a couple of other restrictions discussed below, results in an analytic sample size of 16,641 .

There are six questions concerning access to legal abortion that have been asked consistently since 1972 . These ask whether a woman should be allowed to obtain a legal abortion if (1) she is unmarried and does not want to marry the father of the child; (2) the family has a very low income and cannot afford any more children; (3) she is married and does not want any more children; (4) she became pregnant as the result of rape; (5) the woman's health is seriously endangered by the pregnancy; (6) or there is a strong chance of a serious defect in the baby. The responses to these questions are no (coded as 0 ) and yes (coded as 1 ). Note that the first three items assess abortion for elective reasons and the next three items assess abortion for traumatic reasons.

Although we argue that elective and traumatic abortion are distinct categories culturally and therefore posit two dimensions underlying abortion attitudes, it is still important to assess the statistical properties of these items (cf. Gillespie et al. 1987, 1988). We do this by employing latent class factor analyses that are designed to assess the measurement properties of binary response items (Vermunt and Magidson 2000). The results of these analyses are shown in Table 1 . They confirm that two distinct latent variables underlie abortion attitudes. The first latent variable involves positive responses to the elective abortion items. The second involves negative responses to the traumatic abortion items. Additional analyses indicate that the two factor model is a marked improvement over the one factor model (difference in $\chi^{2}=7,581.1, d f=7, \mathrm{p}<.001$; BIC (one factor) $=7,433.7, \mathrm{BIC}$ (two factors) $=-79.8$ ). The presence of two factors was verified using a variety of statistical approaches designed for binary and latent variables. 4

In order to identify religious traditions, we adopt the approach developed by Steensland, Park, Regnerus, Robinson, Wilcox and Woodberry (2000) to cate-

${ }^{4}$ We took several additional steps to verify the number of latent variables revealed by our latent class analysis. Analyses using the following procedures confirmed that two dimensions that gauge abortion for elective and traumatic reasons consistently underlie the set of six abortion items: A nonparametric Cochran's $Q$ test; a maximum likelihood factor analysis model with the six items using tetrachoric correlations; an item response (IR) model (Raudenbush and Sampson 1999) using a multilevel logistic regression analysis; and a bootstrapping procedure that used a series of random five percent subsamples. Additional details of these verification exercises are available from the first author upon request. 
Table 1. Latent Class Factor Analysis of Abortion Attitude Items, General Social Surveys, 1972-2002

\begin{tabular}{lcc}
\hline Variable & Factor 1 loading & Factor 2 loading \\
\hline Unmarried & 0.95 & 0.22 \\
Low income & 0.96 & 0.31 \\
Married & 0.96 & 0.26 \\
Rape & 0.36 & 0.90 \\
Health & 0.22 & 0.98 \\
Defect & 0.37 & 0.93 \\
\hline
\end{tabular}

Note: The sample size is 16,641 .

gorize Evangelicals and members of other religious traditions in the U.S. Their approach categorizes GSS respondents into Evangelicals, Mainline Protestants, Catholics, Jewish, other religious groups, and nonaffiliates. Since nonaffiliates do not normally attend religious services, we exclude them from the analysis. Moreover, we exclude those categorized as Jewish since their cultural role in debates over abortion is uncertain. Although the Steensland et al. scheme is appealing, especially in its ability to specify Evangelicals, it suffers from a key limitation: It collapses what others have categorized as moderate and liberal Protestants into one mainline category. Considering the different trends in abortion attitudes found in previous studies that have separated liberal and moderate Protestants (e.g., Hoffmann and Miller 1997), it may be unwise to collapse these two groups into one mainline category. Hence, we split the mainline category into liberal and moderate Protestant groups. Details about these two groups are provided in Smith (1990). In the regression models, Catholics are the omitted reference group since previous studies indicate a liberalizing trend among this group that, officially speaking, has among the strictest views on abortion (Jung and Shannon 1988).

Based on previous research on abortion attitudes (e.g, Hoffmann and Miller 1997), we include the following control variables in the analysis: Sex (male $=0$, female $=1$ ), marital status (not married $=0$, married $=1$ ), native southern resident (lived in south at age 16 and at time of survey $=1$; else $=0$; U.S. Census Bureau classification), college attendance (no $=0$; yes $=1$ ), family income (coded as deviations from within-year means), size of place (coded into quartiles), and political ideology (two dummy variables, liberal and conservative, with moderate as the reference category). Since a key interest is in changes over time and by cohort, we include year of survey and birth year of respondent in the models. Moreover, since we suspect that changes by period or by cohort may vary among the abortion items, we include quadratic terms for each in the models. We used centered terms to attenuate the risk of collinearity. 
The multivariate analysis extends the latent class analysis by including covariates in a regression model. Hence the latent classes of abortion attitudes are preserved, but are predicted in a structural equation context by the key explanatory variables. The latent variables are measured so that higher values indicate greater support for legal abortion. To determine the impact of period and cohort on abortion attitudes, we include the year of survey and year of birth in each model. This allows a straightforward disaggregation of period and cohort effects (Firebaugh 1997). Moreover, to determine whether the religious groups have converged or diverged in their attitudes toward abortion, we include interaction terms between religious tradition and year and religious tradition and cohort. Model fit is gauged by Akaike's Information Criterion (AIC), with smaller values indicating a better fit.

\section{RESULTS}

Table 2 presents descriptive statistics for the explanatory and control variables. Evangelicals and Catholics each make up about 30\% of the sample, with smaller groups of moderate Protestants, liberal Protestants, Black Protestants, and affiliates of other religious denominations. About $60 \%$ of the sample is female. Although this is higher than the GSS as a whole, it is important to remember

Table 2. Descriptive Statistics, General Social Surveys, 1972-2002

\begin{tabular}{lcccc}
\hline Variable & Mean & S.D. & Min. & Max. \\
Year of survey & 1987.2 & 9.2 & 1972 & 2002 \\
Year of birth & 1940.5 & 19.1 & 1884 & 1984 \\
Evangelical & .29 & .45 & 0 & 1 \\
Moderate Protestant & .13 & .34 & 0 & 1 \\
Liberal Protestant & .11 & .33 & 0 & 1 \\
Catholic & .31 & .46 & 0 & 1 \\
Black Protestant & .15 & .36 & 0 & 1 \\
Other religious affiliation & .01 & .11 & 0 & 1 \\
Marital status & .60 & .49 & 0 & 1 \\
Liberal & .20 & .40 & 0 & 1 \\
Moderate & .48 & .50 & 0 & 1 \\
Conservative & .31 & .46 & 0 & 1 \\
Attended college & .42 & .50 & 0 & 1 \\
Native southerner & .32 & .47 & 0 & 1 \\
Female & .61 & .49 & 0 & 1 \\
Family income (centered) & .00 & 2.81 & -9.69 & 6.78 \\
Size of place & 2.56 & .99 & 1 & 4 \\
\hline
\end{tabular}

Note: The sample size is 16,641 . 
172 SOCIOLOGY OF RELIGION

Table 3. Regression Analyses of Intergroup Changes in Elective Abortion Attitudes Over Time and Across Cohorts, by Religious Tradition, General Social Surveys, 1972-2002

\begin{tabular}{|c|c|c|c|c|}
\hline Variable & Model 1 & Model 2 & Model 3 & Model 4 \\
\hline Year & $-.017^{* * * *}$ & $-.018 * * *$ & $-.022 * * *$ & $-.010 * *$ \\
\hline Year squared & .033 & .029 & $.046^{*}$ & $.053 * *$ \\
\hline Cohort & $.007^{* * *}$ & $.011 * * *$ & $.005 * * *$ & $.006^{* * *}$ \\
\hline Cohort squared & $-.034^{*}$ &. $.035^{*}$ &. .011 & -.023 \\
\hline \multicolumn{5}{|l|}{ Religious tradition 1} \\
\hline Evangelical & & $-.238 * * *$ & .052 &. .010 \\
\hline Moderate & & $.626^{* * *}$ & $.756^{* * *}$ & $.702 * * *$ \\
\hline Liberal & & $1.133 * * *$ & $1.163 * * *$ & $1.119 * * *$ \\
\hline Black & & .053 & $.185^{* *}$ & $.170^{*}$ \\
\hline \multicolumn{5}{|l|}{ Control variables } \\
\hline Female & & & -.012 & -.014 \\
\hline Married & & & $-.251 * * *$ & $-.249 * * *$ \\
\hline Size of place & & & $.266^{* * *}$ & $.272 * * *$ \\
\hline Liberal ${ }^{5}$ & & & $.449 * * *$ & $.170^{*}$ \\
\hline Conservative $^{2}$ & & & $-.258 * * *$ & $.170^{*}$ \\
\hline Attended college & & & $.400 * * *$ & $.170^{*}$ \\
\hline Native southerner & & &. $.209 * * *$ & $.170^{*}$ \\
\hline Family income & & & $.168 * * *$ & $.170^{*}$ \\
\hline \multicolumn{5}{|l|}{ Interactions by year } \\
\hline Evangelical * year & & & & $-.030 * * *$ \\
\hline Moderate $*$ yeat & & & & -.014 \\
\hline Liberal * year & & & & $-.023 * *$ \\
\hline Black * year & & & & .002 \\
\hline \multicolumn{5}{|l|}{ Interactions by year } \\
\hline Evangelical * year & & & & -.001 \\
\hline Moderate * year & & & & -.002 \\
\hline Liberal * year & & & &. .003 \\
\hline Black * year & & & & .005 \\
\hline $\mathrm{AIC}$ & 2.57 & 2.53 & 2.51 & 2.50 \\
\hline
\end{tabular}

Note: The models were estimated with latent class regression models. The sample size is 16,085 . The coefficients associated with other religious traditions are omitted because they represent such a diverse subgroup and the within-year sample sizes were small.

${ }^{1}$ The comparison group is Catholics.

${ }^{2}$ The comparison group is self-reported political moderates.

${ }^{*} \mathrm{p}<.05 ; * * \mathrm{p}<.01 ; * * * \mathrm{p}<.001$ (2-tailed tests). 
that the analytic subsample consists of those who attend religious services, most of whom are women.

Table 3 provides the results of the latent class regression models with attitudes toward elective abortions as the outcome variable. The first model includes only year and cohort effects. It indicates that there has been a period effect that shows diminished support for elective abortion. This period effect is counteracted by a positive cohort effect indicating that more recent birth cohorts are more supportive of the availability of abortion for elective reasons. However, this positive cohort effect has decreased, as shown by the negative cohort squared coefficient. Using decomposition techniques recommended by Firebaugh (1997), the results of model 1 suggest that the year effects are about twice the cohort effects; thus, there has been an overall decrease in support for legally available elective abortions.

Models 2 and 3 show the regression results once religious tradition and a set of control variables are included. Moving from model 2 to model 3, we see that Evangelicals no longer differ from Catholics in their attitudes toward elective abortion. An auxiliary analysis indicates that the fact that Evangelicals are more likely than others to be native southerners explains the general association between Evangelicals and abortion attitudes. However, there may still be some interesting trends to consider.

Model 4 includes the group by year and group by cohort interactions designed to determine whether there have been differential changes in attitudes across groups. Two interaction terms are significant: Evangelical * year and liberal Protestant * year. They indicate that Evangelicals have become less supportive than Catholics of the availability of elective abortions over time. ${ }^{5} \mathrm{~A}$ similar trend appears for liberal Protestants, but since they are, on average, much more supportive than Catholics, it is likely that the negative coefficient indicates a decreasing gap between Catholics and liberal Protestants.

In order to explore these differential period effects, Figure 1 provides the estimated probability of opposition to abortion over the period 1972-2002. It is clear that Evangelicals have been moving away from Catholics in opposition to elective abortions, at least since the mid-1980s. An auxiliary analysis that splits years into the 1970s, 1980s, and 1990s, indicates that the gap between Evangelicals and Catholics widened considerably in the 1990s; the rate of increase was about $50 \%$ higher in the 1990s than in the 1980s. Hence we find support for the hypothesis that a divergence between Evangelicals and other groups became more prominent in the 1990 s than in earlier periods. The diminishing gap between liberal Protestants and Catholics is due largely to the former's increasing opposition to elective abortions. In fact, the increasing opposition among liberal Protestants is fascinating in its own right, and suggests that the putative liberal-

${ }^{5}$ We explored whether the differential period shifts among Evangelicals were due to shifts in area of residence or area of origin, but found that they were not. 
Figure 1. Predicted Elective Abortion Attitudes, by Year, GSS 1972-2002

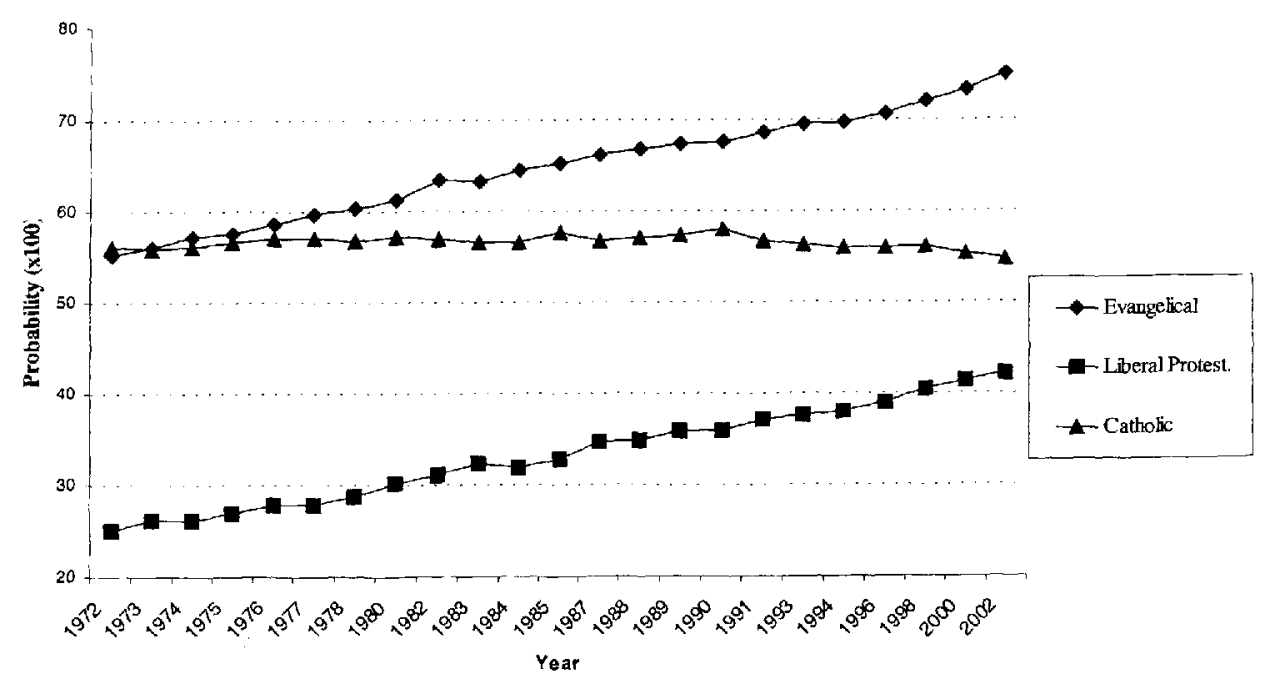

Note: The predicted probability indicates the probability of being in opposition to elective abortions.

ization of abortion attitudes is limited mainly to more secularized subgroups of the U.S. population.

Table 4 presents the results of the latent class regression models with attitudes toward traumatic abortions as the outcome variable. The initial results are similar to those in Table 3. There has been a decrease in support for abortion for traumatic reasons over time, but an increase across cohorts. Decomposing these effects suggests that the period effects are about twice those of the cohort effects. Model 2 is also similar to its counterpart in Table 3, except that the difference between Evangelicals and Catholics is not significant. However, once the control variables are introduced, a significant difference between Evangelicals and Catholics emerges. On average, Evangelicals are less likely than Catholics to support legal abortions for traumatic reasons. Liberal and moderate Protestants are more supportive of abortion for these reasons than either Catholics or Evangelicals.

The trend analyses offer mixed support for the second hypothesis (see Model 4). First, as expected, younger cohorts are more likely than older to support legal abortions for traumatic reasons. Second, contrary to expectations, the negative cocfficient for Evangelical * year suggests that Evangelicals have become less supportive of abortion for traumatic reasons over time relative to Catholics. Third, the gap by cohort between Evangelicals and Catholics has also increased. In order to sort out these diverging trends, Figures 2 and 3 present the predicted proba- 
Table 4. Regression Analyses of Intergroup Changes in Traumatic Abortion Attitudes Over Time and Across Cohorts, by Religious Tradition, General Social Surveys, 1972-2002

\begin{tabular}{|c|c|c|c|c|}
\hline Variable & Model 1 & Model 2 & Model 3 & Model 4 \\
\hline Year & $-.019 * * *$ & $-.020 * * *$ & $-.018 * * *$ & $-.012 * *$ \\
\hline Year squared & .014 & -.028 & -.042 & -.022 \\
\hline Cohort & $.009 * * *$ & $.013 * * *$ & $.010 * * *$ & $.019 * * *$ \\
\hline Cohort squared & .014 & .009 & .035 & $.053^{*}$ \\
\hline \multicolumn{5}{|l|}{ Religious tradition 1} \\
\hline Evangelical & & .099 & $.210 * * *$ & $.148^{*}$ \\
\hline Moderate & & $1.526^{* * *}$ & $1.624 * * *$ & $1.540 * * *$ \\
\hline Liberal & & $2.091 * * *$ & $2.051 * * *$ & $2.080 * * *$ \\
\hline Black & & -.113 & -.130 & -.073 \\
\hline \multicolumn{5}{|l|}{ Control variables } \\
\hline Female & & & .004 & .011 \\
\hline Married & & & $-.289 * * *$ & $-.275 * * *$ \\
\hline Size of place & & & $.158^{* *}$ & $.168 * * *$ \\
\hline Liberal $^{2}$ & & & $.271^{* * *}$ & $.254 * * *$ \\
\hline Conservative $^{2}$ & & & $-.496 * * *$ & $-.499 * * *$ \\
\hline Attended college & & & .086 & .066 \\
\hline Native southerner & & & .038 & .021 \\
\hline Family income & & & $.074 * * *$ & $.077 * * *$ \\
\hline \multicolumn{5}{|l|}{ Interactions by year } \\
\hline Evangelical * year & & & & $-.018 * *$ \\
\hline Moderate ${ }^{*}$ year & & & & -.004 \\
\hline Liberal * year & & & &. $.043^{*}$ \\
\hline Black * year & & & & .014 \\
\hline \multicolumn{5}{|l|}{ Interactions by year } \\
\hline Evangelical * year & & & & $-.024 * * *$ \\
\hline Moderate * year & & & & $-.013^{*}$ \\
\hline Liberal * year & & & & -.006 \\
\hline Black * year & & & & .005 \\
\hline AIC & 2.20 & 2.15 & 2.51 & 2.09 \\
\hline
\end{tabular}

Note: The models were estimated with latent class regression models. The sample size is 16,641 . The coefficients associated with other religious traditions are omitted because they represent such a diverse subgroup and the within-year sample sizes were small.

1 The comparison group is Catholics.

${ }^{2}$ The comparison group is self-reported political moderates.

$* \mathrm{p}<.05 ; * * \mathrm{p}<.01 ; * * * \mathrm{p}<.001$ (2-tailed tests). 
bility of opposition to abortion for traumatic reasons for Catholics, Evangelicals, and either liberal or moderate Protestants.

Figure 2 demonstrates that Evangelicals and Catholics have crossed in their opposition to abortion for traumatic reasons. In the 1970s and early 1980s, Catholics were more opposed to these types of abortions, but this switched in the 1990s so that Evangelicals became less supportive than Catholics. Nonetheless, note that opposition to traumatic abortions in substantially lower than opposition to elective abortions.

Figure 3 shows the changes in attitudes by birth cohort. The crossing pattern depicted in Figure 2 also occurs in Figure 3. Catholics born in the first half of the 20th century were more opposed than Evangelicals born during the same time period to these types of abortions. However, in more recent birth cohorts this has switched. Hence, opposition to elective and traumatic abortions among Catholics of a younger generation has waned (Sullins 1999). Moreover, it is clear that the gap between Evangelicals and moderate Protestants has also increased. In fact, rerunning the models shown in Tables 3 and 4 and using liberal or moderate Protestants as the reference group indicates that the Evangelical divergence generalizes across all of the comparisons. It is clear that Evangelicals have increased their opposition to both elective and traumatic abortions relative to other religious traditions over time, but also, at least when considering traumatic abortions, across cohorts.

Figure 2. Predicted Traumatic Abortion Attitudes, by Year, GSS 1972-2002

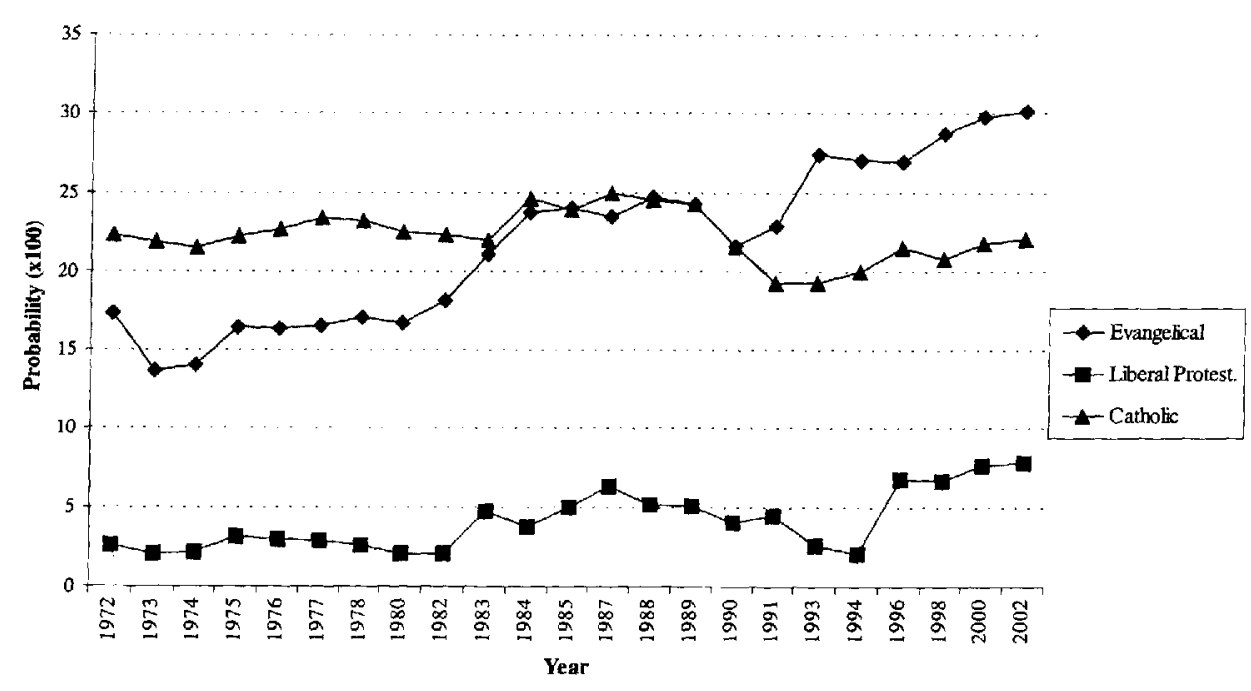

Note: The predicted probability indicates the probability of being in opposition to traumatic abortions. 
Figure 3. Predicted Traumatic Abortion Attitudes, by Birth Cohort, GSS 1972-2002

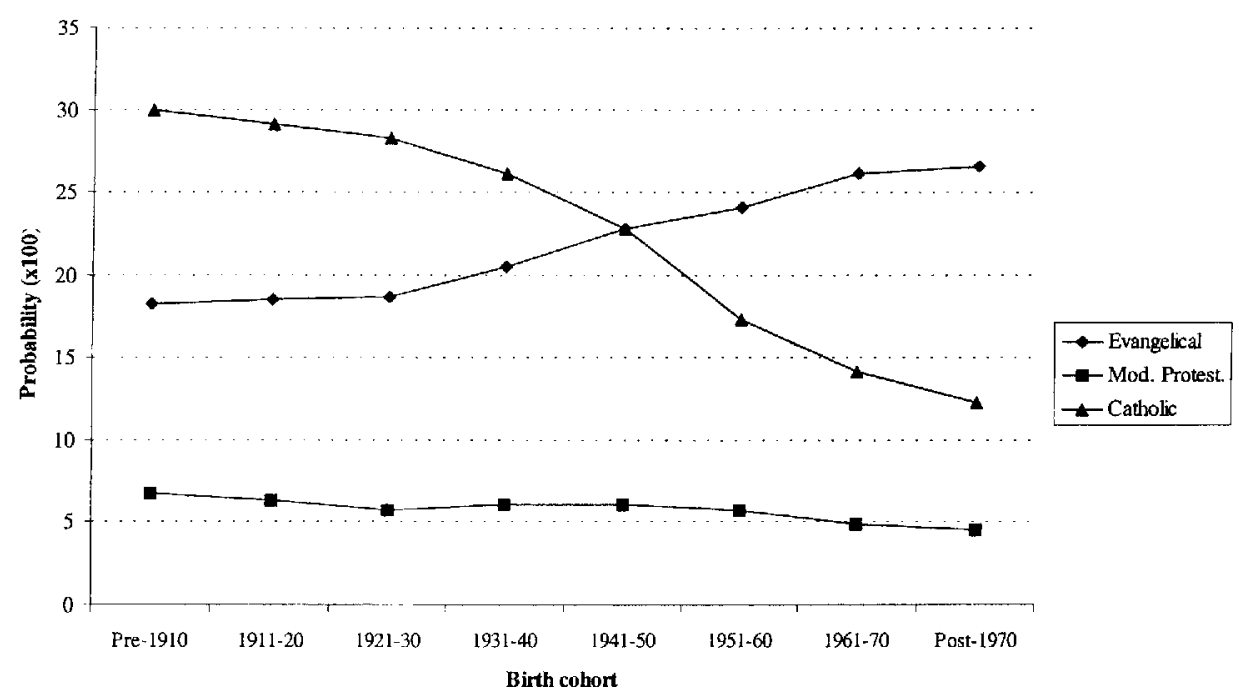

Note: The predicted probability indicates the probability of being in opposition to traumatic abortion.

\section{DISCUSSION}

The controversy over abortion in the United States continues virtually unabated. The recent debate over partial birth abortion serves only to reinforce the ideological depth of this controversy. Religious traditions have played a key contributory role in perpetuating conflicts about this nettlesome issue. Yet most social science attention to abortion attitudes and policy has failed to consider some important cultural characteristics that affect members of diverse religious traditions. In particular, members of religious traditions tend to distinguish between traumatic or elective explanations when making assessments about abortion. This led us to different expectations concerning changes in abortion attitudes among adherents of various religious traditions. In particular, specific historical events, cultural shifts, and rhetoric about abortion, as well as studies mapping changes in these over the last 30 years, led to the hypothesis that a divergence between Evangelicals and members of other traditions mainly concerned attitudes toward abortion for elective reasons. We also proposed that the relative positioning of attitudes toward abortion for traumatic reasons has not shifted much across religious traditions. We posited that the primary divergence was limited to birth cohorts as younger cohorts became relatively more supportive of legal abortions for traumatic reasons. 
The results of the empirical models provide mixed support for the hypotheses. There is considerable evidence that the gap between Evangelicals and other groups concerning attitudes toward elective abortion widened significantly, especially during that late $1980 \mathrm{~s}$ and $1990 \mathrm{~s}$. Catholics have maintained a steady level of opposition to this type of abortion, but Evangelical opposition has clearly increased. However, even liberal Protestants, beginning from a low baseline, increased their opposition to elective abortions over the last 30 years. We surmise that these trends are due to a variety of cultural factors, such as the continuing prevalence of abortions in the U.S., the presumed political indifference to federal and state policies designed to curb abortions, and the Supreme Court's unwillingness to overturn Roe $v$. Wade. This latter issue, given that many thought the Supreme Court had several opportunities in the late 1980s and early 1990 s to right a perceived wrong, may have been especially troubling to myriad Evangelicals, particularly after the Reagan administration had presumably supported so many of their causes. The increasing opposition among Evangelicals may also reflect religious switching: Those who hold more conservative views about abortion are finding a more comfortable faith-based niche in Evangelical churches.

The hypothesis concerning traumatic abortions was only partially supported. We proposed few changes among religious traditions in their attitudes toward these types of abortions. Considering that most groups permit-or at least will discuss-abortions when the mother's health is at risk or when the pregnancy occurred because of rape (e.g., Assemblies of God 1985), we posited that the main vehicle driving changes in attitudes toward traumatic abortion involved cohort shifts. Although this is partially true, there are also some interesting results concerning changes among religious traditions. In particular, Evangelicals have not only become more opposed to elective abortions relative to other groups, but they have also increasingly opposed abortion for traumatic reasons.

It is not entirely clear what might be driving this Evangelical cohort shift, especially since it is at odds with more general cohort shifts in the GSS toward greater support for legal abortion under traumatic circumstances. Nonetheless, it helps elaborate recent evidence that those coming of age during the Reagan administration are generally less supportive of access to legal abortion (Cook et al. 1993). The distinctive view many younger Evangelicals have about abortion in general is likely driving this finding (Sullins 1999). The pro-life movement's consistent rhetoric condemning all types of abortions has become so generalized in the community of younger Evangelicals that abortion is perceived by many as a monolithic issue. The increasing public awareness in the Evangelical community about how to address political and social injustices-which presumably includes abortion-has caught on more among recent generations of Evangelicals than among earlier generations (Regnerus and Smith 1998). Whereas other religious traditions--including their younger members-continue to distinguish the types of abortion about which they should be concerned, or 
are more likely to see the abortion decision as private and thus preferably out of the reach of legal intervention, Evangelicals, who comprise much of the pro-life movement in the U.S., increasingly sense that the prevalence of all types of abortions is detrimental to the nation's moral fabric. Their strong opposition to abortion also allows them to maintain a high degree of distinctiveness from the rest of society (McConkey 2001). Recent findings that the variability of Evangelical attitudes about abortion has diminished across education groups and over time supports the notion that abortion has become a more salient unifying issue for Evangelicals in recent years (Evans 2002). Additional research among younger Evangelicals should yield intriguing evidence about how their attitudes and worldviews may be distinct from an older generation.

There are several issues that should be addressed by future research on abortion attitudes. First, it is important to continue to explore some of the generalized attitudes or worldviews that accompany permissive or restrictive views of abortion. Research suggests that permissive abortion attitudes accompany more lenient views about sexual behavior, progressive attitudes about women's roles, and a more liberal disposition (Jelen and Wilcox 1997). Since the abortion debate was redefined early in the ideological process as involving primarily the right of women to "control their own lives" (Luker 1984:118), it is not surprising that these attitudes are part of a general construct. It is therefore worthwhile for future studies to seek a better understanding of the methods by which constituents' worldviews affect their moral concerns and how this varies by religious tradition.

Second, it is important to explore in more detail the messages about abortion that are delivered to religious affiliates. The negative period effect is counteracted by a cohort effect that favors access to legal abortion. Yet, a younger generation of Evangelicals is clearly challenging this trend by their increasing opposition to abortion, in particular abortion for traumatic reasons (cf. Figure 3 and Sullins 1999). Is the message that is being inculcated among the more recent generation of Evangelicals different than the messages heard by their parents? Was an earlier generation more comfortable distinguishing the types of abortion? In-depth interviews with younger and older Evangelicals would shed light on these and other generationally-relevant questions.

Third, what impact do views of biblical inerrancy have on abortion attitudes? Abortion rights advocates are fond of pointing out that the Bible does not explicitly prohibit abortion. Pro-lifers usually respond that the Old Testament exhortation "Thou shalt not kill" suffices to protect the fetus. Given that there is not an explicit biblical prohibition, however, it is not clear what effect beliefs about biblical literalism might have on changing abortion attitudes among religious traditions. Unfortunately, the GSS does not ask questions about biblical literalism with sufficient frequency to satisfactorily explore this issue.

Finally, there is the more general question about how the wording of the abortion items affects response patterns. The GSS questions ask about "legal 
abortion" under a particular set of circumstances. Hence, if the term "abortion" triggers cognitive cues differentially among members of various religious traditions, the pattern of change may be affected by the way that these cues are formulated and used. Words can have a powerful effect on the way survey respondents answer questions (Miller and Hoffmann 1999; Tourangeau, Rips, and Rasinski 2000). It is therefore important to ask what the shifts in attitudes might have looked like if a term like "termination of pregnancy" was used instead of abortion. Or, suppose that the term "legal" was omitted? Would that have changed the way respondents answered the questions?

Although each of these issues is crucial if we are to fully understand how cultural change has affected shifts in attitudes toward abortion, it is apparent that there have been differential shifts among religious affiliates. In particular, the increasing opposition among Evangelicals to both elective and traumatic abortion suggests that their subculture has entrenched or increased its distinctiveness about at least one issue that has powerful moral, political, and social underpinnings. The moral complexities of the abortion issue and its symbolic value as a marker for societal degradation have led to an increasing division between Evangelicals and other religious adherents. Whether this division will continue in future years is uncertain, although the potent moral certitude of the Evangelical community suggests that it will.

\section{REFERENCES}

Ammerman, N.T. 1990. Baptist battles: Social change and religious conflict in the Southern Baptist Convention. New Brunswick, NJ: Rurgers University Press.

Assemblies of God. 1985. A biblical perspective on abortion. Springfield, MO: General Council of the Assemblies of God.

Christian Century. 1991. ELCA statements against abortion. Christian Century 108:841 (September 18-25).

Christianity Today. 1984. Mainline churches reassess prochoice stand on abortion. Christianity Today 28:72 (December 14).

Cook, E.A., T.G. Jelen, and C. Wilcox. 1992. Between two absolutes: Public opinion and the politics of abortion. Boulder, CO: Westview Press.

1993. Generational differences in artitudes toward abortion. American Politics Quarterly 21:31-53.

Dillon, M. 1995. Religion and culture in tension: The abortion discourses of the U.S. Catholic Bishops and the Southern Baptist Convention. Religion and American Culture 5:159-180.

1996. The American abortion debate: Culture war or normal discourse? In The American culture wars: Current contests and future prospects, edited by J. Nolan, 115-132. Charlottesville, VA: The University Press of Virginia.

Dobson, E.G. 1988. Abortion. Fundamentalist Journal 7:26-61.

Dunnett, D.E. 1990. Evangelicals and abortion. Journal of the Evangelical Theological Society $33: 215-225$.

Evans, J.H. 2002. Polarization of abortion attitudes in U.S. religious traditions, 1972-1998. Sociological Forum 17:397-422.

Falwell, J. 1986. If I should die before I wake. Nashville, TN: Thomas Nelson Publishers.

Firebaugh, G. 1997. Analyzing repeated surveys. Thousand Oaks, CA: Sage. 
Frame, R. 1989. Presbyterians consider four views of abortion. Christianity Today 33:52-55 (December 15).

Gillespie, M.W., E.M. Ten Vergert, and J. Kingma. 1987. Using Mokken scale analysis to develop unidimensional scales: Do the six abortion items in the NORC GSS form one or two scales? Quality and Quantity 21:393-408.

. 1988. Secular trends in abortion attitudes: 1975-1980-1985. Joumal of Psychology 122:323-341.

Harris, R.J., and E.W. Mills. 1985. Religion, values, and attitudes toward abortion. Joumal for the Scientific Study of Religion 24:137-154.

Heim, D. 1988. American Baptists maximize the middle. Christian Century 105:660-662 (July 20-27).

Hoffmann, J.P., and A.S. Miller. 1997. Social and political attitudes among religious groups: Convergence and divergence over time. Journal for the Scientific Study of Religion 36:52. 70 .

1998. Denominational influences on socially divisive issues: Polarization or continuity? Journal for the Scientific Study of Religion 37:528-546.

Huckfeldt, R., and J. Sprague. 2000. Political consequences of inconsistency: The accessibility and stability of abortion attitudes. Political Psychology 21:57-79.

Hunter, J.D. 1994. Before the shooting begins: Searching for democracy in America's culture war. New York: The Free Press.

Jelen, T.G. 1988. Changes in attitudinal correlates of opposition to abortion, 1977-1985. Joumal for the Scientific Study of Religion 27:211-228.

Jelen, T.G., and C. Wilcox. 1997. Attitudes toward abortion in Poland and the United States. Social Science Quarterly 78:907-921.

Jung, P.B., and T.A. Shannon. 1988. Abortion and Catholicism: The American debate. New York: Crossroad.

Kucharsky, D.E. 1973. New style NCC: Stalling on abortion, eyeing the Jews. Christianity Today 17:44-45 (March 30).

Lewis, L.L. 1997. Proclaiming the pro-life message: Christian leaders address the abortion issue. Garland, TX: Hannibal Books.

Luker, K. 1984. Abortion and the politics of motherhood. Berkeley, CA: University of California Press.

McConkey, D. 2001. Whither Hunter's culture war? Shifts in evangelical morality, 1988-1998. Sociology of Religion 62:149-174.

Miller, A.S., and J.P. Hoffmann. 1999. The growing divisiveness: Culture wars or a war of words? Social Forces 78:721-745.

Mouw, T., and M.E. Sobel. 2001. Culture wars and opinion polarization: The case of abortion. American Journal of Sociology 106:913-943.

Nolan, J.L. (ed.). 1996. The American culture wars: Current contests and future prospects. Charlottesville, VA: The University Press of Virginia.

O'Connor, K. 1996. No neutral ground? Abortion politics in an age of absolutes. Boulder, CO: Westview Press.

Petersen, L.R. 2001. Religion, plausibility structures, and education effects on attitudes roward elective abortion. Journal for the Scientific Study of Religion 40:187-203.

Powell, J. 1981. Abortion: The silent holocaust. Chicago: Thomas More Press.

Presbyterian Church-USA. 1992. Problem pregnancies and abortion. Church and Society 82:19-29.

Raudenbush, S.W., and R. Sampson. 1999. Assessing direct and indirect effects in multilevel designs with latent variables. Sociological Methods 8 Research 28:123-153.

Regnerus, M.D., and C. Smith. 1998. Selective deprivation among American religious traditions: The reversal of the great reversal. Social Forces 76:1347-1372. 


\section{SOCIOLOGY OF RELIGION}

Rochon, T.R. 1998. Culture moves: Ideas, activism, and changing values. Princeton, NJ: Princeton University Press.

Rudy, K. 1996. Beyond pro-life and pro-choice: Moral diversity in the abortion debate. Boston: Beacon Press.

Russo, N.F., and J.E. Denious. 1998. Why is abortion such a controversial issue in the United States? In The new civil war: The psychology, culture, and politics of abortion, edited by L.J. Beckman and S.M. Harvey, 25-59. Washington, DC: American Psychological Association.

Schlossberg, T., and E. Achtemeier. 1995. Not on my oun: Abortion and the marks of the church. Grand Rapids, MI: Eerdmans Publishing.

Scott, J. 1989. Conflicting beliefs about abortion: Legal approval and moral doubts. Social Psychology Quarterly 52:319-326.

Seventh-day Adventists. 1992. Guidelines on abortion. Silver Spring, MD: General Council of Seventh-day Adventists.

Smith, C. 2000. Christian America? What evangelicals really want. Berkeley, CA: University of California Press.

Smith, T.W. 1990. Classifying protestant denominations. Review of Religious Research 31:225245.

Sørenson, A.B. 1998. Theoretical mechanisms and the empirical study of social processes. In Social mechanisms: An analytical approach to social theory, edited by P. Hedström and R. Swedberg, 238-266. Cambridge: Cambridge University Press.

Steensland, B., J.Z. Park, M.D. Regnerus, L.D. Robinson, W.B. Wilcox, and R.D. Woodberry. 2000. The measure of American religion: Toward improving the state of the art. Social Forces 79:291-318.

Sullins, D.P. 1999. Catholic/Protestant trends on abortion: Convergence and polarity. Journal for the Scientific Study of Religion 38:354-369.

Tourangeau, R., L.J. Rips, and K. Rasinski. 2000. The psychology of survey response. New York: Cambridge University Press.

United Methodist Church. 2000. Abortion. In The book of discipline of the United Methodist Church, 21-24. Nashville, TN: Abingdon Press.

Vermunt, J.K., and J. Magidson. 2000. Latent gold user's guide. Belmont, MA: Statistical Innovations.

Wilcox, C. 1995. The sources and consequences of public attitudes toward abortion. In Perspectives on the politics of abortion, edited by T.G. Jelen, 55-86. Westport, CT: Praeger.

Woodrum, E., and B.L. Davison. 1992. Reexamination of religious influences on abortion attitudes. Review of Religious Research 33:229-243.

Yancey, P. 1994. The riddle of Bill Clinton's faith. Christianity Today 38:24-29 (April 25).

Zucker, G.S. 1999. Attributional and symbolic predictors of abortion attitudes. Joumal of Applied Social Psychology 29:1218-1245. 